\section{(D) hertuations}

on

\section{HYPERGLYCAEMIA AND GLYCOSURIA.* BY}

H. J. HAMBURGER, D.Sc., M.D., LE.D., F.R.S., PROFESSOR OF PHYSIOLOGY IN THE UNIVERSITY OF GRONINGEN,
HOLLAND.

\section{Introduction.}

Since the time of Claude Bernard it has been known that sugar is never absent from the blood, and that it rarely if ever appears in the urine of normal individuals. What is the canse of this, and why does sugar appear in the urine when its presence in the blood exceeds a certain limit? These are questions which should be of interest nat only to the physiologist but also and especially to the clinic.

Several possibilities that would explain the absence of sugar in the normal urine have been considered. In the first place, that, in a normal individual, glucose passes through the glomeralar membrane and is further burnt up in the kidney. 'This supposition seems to me to be very improbable. It is true that in the kidneys the oxidation is very powerfal, but, on the other hand, if the question is viewed in the light of efficiency, it is difficult to bring onewelf to agree with this conception. For is not sugar the nearest soarce for muscular worls?

In the second place, it may be inagined that the glucose, after haviug made its way through the glomerular mem. brane into the intercapsular space, is there resorbed by the surrounding blood vessels. Neitler is this suggestion acceptable, for here we would have to do with a waste of energy.

Thirdly, there may be the possibility that the sugar cannot pass through the glomerular epithelium, the reason being that it is present in the blood plasma as a colloidal com. pound-a compound of glucose, which is of itself not a colloid-with a substance which occurs in the blood plasma. If the quantity of glucose in the plasma has become so great that there is an insufficiency of the other substance to bind it all, free glucose will circulate with the blood plasma, and so pass through the glomerular epithelium into the urine; the result is glycosnria. Especially have Lépine and his co-workers defended this theory very ably. The compounded sugar he called sucre virtuel, and the free sugar sucre actuel.

In the meantime difficulties have been raised in con. nexion with the retention of the sugar in the colloidal state. Asher and Rosenfeld, and later, by an improved method, Michaelis and Kona, showed that when serum containing glucose is brought into a tube of parcliment paper the sugar diffuses through it. 'This would not have taken place if the sugar had been in the form of a colloidal compound. From this they concluded that sugar does not occur in the blood as a colloid.

John Abel comes to the same conclusion with his socalled vividiffusion experiments. In his researches a connexion was brought about between an artery and its acconopanying vein by weans of a collodion tube, which he surrounded with a wider glass tube containing an isotonic colt solution. It appeared that through sueh a collodion membrane sugar diffused. These experiments have created a deep impression, and it appeared as if by them there had come $a$ dead stop.

Still it seemed to us that the presence of a colloidal componnd in the blood plasma had not been absolutely disproved by these experiments, because there is always the possibility that the writers erroneously took that which passed through their membranes for simple sugar, although it gave the tests for sugar. Moreover, it is not admissible to consider the permeability of collodion and parchment, as such, as being the same as that of the glomerular epitheliam. Has not Bechlold taught us that some colloidal substances axe let through and others not by the same membrane, and vice versa, that the same colloidal substance can pass throngh a particular men.

* This article is a summary of a series of researches that have been conducted during the course of the last three vears in the physioogreal laboratory here in co-operation with Dr. R. Brinkman, assistant in the laborators are not easily accesstble to the majority of readers of this Ioverich Part v, which treats of the toleration of the kidneys for sugar, and Part VI, of the behaviour of the kidneys tnwards some isonteric sugars, have not hitherto been vublished. brane and not through another? Wre recall the researches of W. Brown pubtished in the Biochemical Journal, 9 (1915), on the different permeability of collodion mem. branes even to different inorganic salts. We could there fore not accept it as being definitely proved that sugar. occurs in tire blood in an absalutely free state. Consequently we considered it desirable to investigate systematically whether, notwithstauding the results of the diffusion experiments, the theory of a colloidal suga: compound was not after all correct.

Does the Kidney Allow the Passage of Free Glucose?

With this end in view, we decided in the first place to answer the fundamental question, which had up to this not yet been considered: whether the kidney allowed free glucose to pass through or not.

Experiments were made with the isolated kidney. To ensure that the perfusion liquid contained exclusively free sugar, Ringer's solation containing sugar was taken. If it proved that the concentration of sugar in the so-formed artificial urine was the same as that of the original hiquid the conclusion could be drawn that the kidney is permeable to glucose. After this it could be determined whether the addition of serum would cause a retention of sugar. Should this be the case it would be practically certain that there is present in the serum a substance which binds the sugar and brings it into a form that the glomerular epithelium does not allow to pass through, and eventually it could be investigated what this substance in the serum is

With these investigations Dr. Brinkman and I have kept ourselves busy for more than two years. Through them we have come to the most unexpected results, which now and then led us on to sidepaths which, considered from a general point of view, were important in themselves.

\section{I1. Some Technical Details.}

Frogs were exclusively used for the experiments. The conditions for experiments on these animals are mucl simpler than for warm-blooded animals; later, when circumstances will allow a normal use of gas, we shall be able to make experiments on warm-blooded animals also. Big masculine specimens of Rana temporaria were used. After the head has been severed with a pair of scissors the spinal marrow is destroyed by means of a long needle, anil all the organs, except the kidneys, testes, and bladder, re. moved. A fine injection needle is then inserted in the aorta communis, and a fine glass cannula with a bulb into the ureters. This bulb serves as a receiver for the artificial urine, but is not necessary. The liquid which passes through the blood vessels must contain a large amount of oxygen. This bubbles all the while through the perfusion liquid, which stands at a level of $60 \mathrm{~cm}$. above the body of the frog. In this way approximately $150 \mathrm{c.cm}$. flow through the kidneys per hour.

The "urine" is to be considered as a product of the glomeruli.

To grasp this a knowledge of the way the blood ressels run in the frog is needed. In contrast to what we find in warm-blooded animals, the arteria renalis supplies the glomeruli and to a very small extent the tubuli, while tho latter get their blood supply almost wholly from the ven: porta renalis, which carries off the greater part of the blood from the hindquarters. It now appears that if a liquid is made to flow through this vessel under a pres. sure of $60 \mathrm{~cm}$. not a drop of urine is excreted. Excretion takes place only under a much higher pressure, and even then very slowly. It is therefore clear that in our experiments, where the liquid is made to flow throngh the arteria renalis, the urine can be derived from the glomeruli.

The fact that it is possible to separate the products of the glomeruli and tubes so well from each other makes tlio frog an admirable object for the study of the formation of urine.

The perfusion liquid consisted, as has been said, of Ringer's solution, to which had been added a known quantity of glucose. Great care must be bestowed upon the preparation of the solution. Every trace of carbon dioxide must be removed from the water. The flask in which it is kept must be waxed on the inside to prevent the glass from spoiling it. Care was further taken that no carbon dioxide was carried along with. the liquid as it Howed from the flask. None of these precautions may be 
neglected. Lack of knowledge in this connexion has led to repeated failures of experiments. The glucose in the perfusion liquid and the product formed from it by the kidneys was determined by the excellent micro-method of Bang (1916). This method ensures an accurate determination of the amount of glucose present in $1 \mathrm{c.cm}$. of a liquid up to 0.006 per cent.

\section{The Permeability of the Frog's Kidney to} Free Glucose.

The Significance of the Concentration of Calcium and Potassium.

As has been said before, the fundamental question, which had not yet been inquired into, had to be answered -namely, whether the glucose concentration of the urine would be the same as that of a Ringer's solution containing sugar which is passed through the kidney, and from which it is formed. The Ringer's solution had the usual composition : $\mathrm{NaCl} 0.7$ per cent., $\mathrm{NaHCO}_{3} 0.02$ per - cent. KCl 0.01 per cent., $\mathrm{CaCl}_{2} 0.0075$ per cent. Repeated experiments showed that the concentration of glucose in both liquids was absolutely the same, and therefore that the kidney was perfectly permeable to free glucose. It was now expected, in accordance with the idea enter. tained by Lépine about a colloidal sugar compound, that, by the addition of serum to the Ringer-glucose mixture, glucose would be retained, and that there would be less sugar present in the urine than in the original perfusion liquid. 'This, in fact, proved to be the case. Then there suddenly followed a surprise. It appeared that in a mixture of serum with a sixfold quantity of Ringer's solution a considerable quantity of sugar was retained, while with an eightfold quantity none.* This astonishing observation had to be explained, and le 1 to a circumstantial investigation, which finally exhausted the whole supply of Ringer's solution. A fresh solution had to be made therefore. This brought us face to face with another surprise for when, for safety's sake, the experiment was started from the beginning again with this new solution to which no serum had yet been added-this being reserved for a later stage-it was found, in contradiction to the results obtained previously, that now glucose was retained. We thought that very likely something was altered in the composition of the Ringer's solution-perhaps the amount of calcium. One is so apt to make a mistake between the anlydrous $\mathrm{CaCl}_{2}$ and that still containing the water of crystallization. 'Thus only the amount of $\mathrm{CaCl}_{2}$ had been altered in the Ringer's solution. Systematic investigations now proved that, when 0.0075 per cent. $\mathrm{CaCl}_{2}$ was used, the "urine" contained 0.07 per cent. sugar ; conse. quently that of the 0.1 per cent. glucose in the solution 0.03 per cent. was retained, while when 0.005 per cent. and 0.010 per cent. $\mathrm{CaCl}_{2}$ was used-that is, less or more than 0.0075 per cent. - the glomerular epithelium allowed all the sugar to pass through.

It appeared consequently that the permeability was to a large extent depeudent upon the concentration of $\mathrm{CaCl}_{2}$ in the perfusion liquid.

This influence of calcium upon the permeability of cells need not surprise us when we recall the experiments made by Chinri in connexion with artificial conjunctivitis. By dropping a solution of $\mathrm{CaCl}_{2}$ into the eye, inflammation is brought to a standstill, and after a minimum of time ceases completely. Again, the haemolysis of red blood corpuscles is prevented by calcium. Calcium luas, if it be permitted to call it so, a "densifying" effect on the surface of the cell.

After these systematic investigations in connexion with the influence of calcium, similar experiments were made with potassium; only the concentration of $\mathrm{KCl}$ in the Ringer's solution was changed. It then appeared that a certain concentration of potassium chloride always answers to a fixed concentration of calcium chloride, and vice versa. If the one is clianged then the other has to be clianged accordingly. They balance each other.

'lih does not sound inconceivable when it is remem bered that potassium has a weakening effect even on gelatin. As has been said, calcium acts astringently. Especially in the case of the frog does potassium act strikingly. In a series of experiments we, saw the red blood corpuscles swell up in a solution of KCl which was isotonic with serum. This swelling is totally absent in an

\footnotetext{
* Compare for the explanation of this especially section IV.
}

isotonic solution of $\mathrm{NaCl}$. The kidney also shows a considerable swelling in an isotonic $\mathrm{KCl}$ solution.

\section{Radium and Uranium and Mesothorium Rays.}

Let it be remarked, by the way, that, perfectly in accordance with the researches of $\mathrm{Z}$ waardemaker and his co-workers in connexion with the heart, here also the radio-active uranium and radium could be substituted for potassium, and that the quantities of uranium and radium are not regulated by the atomic weights of these elements - that is, are not equivalent to each other in a strict chemical sense, but are regulated by the radio-activity of these substances, and this radio-activity is quite independent of the atomic weight. Since radium is radioactive to a great degree and potassium much less, and uranium takes an intermediate position between these two, it is not surprising that an exceptionally small quantity of radium can be substituted for potassium, while the amount of uranium again takes an intermediate place. For retaining the maximum amount of sugar-namely, 0.03 per cent. - there was necessary a solution of uranium nitrate of 0.00015 per cent., and one of radium bromide of 0.0000005 per cent. ; in the presence of more or less of both salts in the Ringer's solution the retentive. power for glucose was nil. The same was observed with regard to the concentration of $\mathrm{KCl}$. If with a concentration of 0.0075 per cent. $\mathrm{CaCl}_{2}$ that of $\mathrm{KCl}$ was 0.01 per cent., then the urine contained 0.03 per cent. less glucose than the perfusion liquid. If a stronger or weaker concentration than 0.01 per cent. was used, then the power of retention was wholly, or almost wholly, lacking.

A simple subjection to mesothorium rays serves the same purpose as $\mathrm{KCl}$. A subjection to these rays brought about also a considerable swelling even of the kidney.

The "balance" idea makes it clear that by application of uranium the so-called uranium glycosuria can be brought about (Pollack), while on the other hand Hughes, and also West, administered with success small quantities of uranium in cases of diabetes. ${ }^{1}$

\section{The Concentration of $\mathrm{NaHCO}_{3}$ in the Perfusion Liquid.}

So far experiments had taught that from the liquid considered the most suitable perfusion liquid, and coutaining 0.1 per cent. glucose, a " urine" containing at least 0.07 per cent. glucose was formed, and that at the most 0.03 per cent. glucose could be retained. To our surprise this retention became still smaller when the concentration of glucose in the solution was weaker. For there was reason to expect if a solution containing 0.03 per cent. sugar was passed through the kidneys the urine formed would be free from glucose. This, however, was not the case. We could not obtain a glomerular filtrate that was free from sugar.

Deeing that the normal concentration of glucose in the frog's blood is: from 0.03 to 0.05 per cent. and the urine of the frog is free from sugar, we put to ourselves the question, whether the Ringer's solution hitherto used was indeed the most physiological. We endeavoured therefore to improve the solution. The influence of $\mathrm{CaCl}_{2}$ and $\mathrm{KCl}$ had already been studied. The obvious course was now to proceed to study the influence of the concentration of the $\mathrm{NaHCO}$

Since the time of $S$. Ringer it has been generally accepted that the $\mathrm{NaHCO}_{3}$ is indispensable for perfusion. Also we had found in the experiments in question that it was necessary for the perfusion liquid. Not a trace of glucose was retained in the absence of $\mathrm{NaHCO}_{3}$. It is known that amongst others the function of the $\mathrm{NaHCO}_{3}$ is to preserve a certain alkalinity of the body fluid, which would ctherwise, in consequence of the constant acid formation, become acid. The sodium phosphate and sodium protein also take a part in this. In this connexion these substances arè consequently called tampons, buffers, regnlator's or moderators. Most investigators use 0.02 per cent. $\mathrm{NaHCO}_{3}$, and we have done the same. It has appeared to us, however, that this concentration is too weak for perfusion through the frog's kidney, for if to the solution made up of NaCí 0.6 per cent., $\mathrm{NaHCO}_{3} 0.02$ per cent., $\mathrm{KCl} 0.01$ per cent., $\mathrm{CaCl}_{2} 0.0075$ per cent., a little neutral red, which is known to be harmless to life, is added, then the alkaline perfusion liquid is orange-yellow, but the " urine:" becomes red, proving that it has become acid. 
What now is the case with the reaction of the normal urine of the frog? If a little of this is pressed out of the bladder of a normal animal, it shows a weak alkaline reaction with neatral red. From this it appears that the buffer concentration of 0.02 per cent. was too weak to keep the reaction a weak alkaline one, as is the case in the normal urine of the frog.

But, what is still more important, as the urine becomes acid the retentive powers of the kidneys for sugar grow considerably weaker and finally disappear altogether.

Inoreased Concentration of $\mathrm{NaHCO}_{3}$.

The best thing, therefore, to do was to make the concentration of the $\mathrm{NaHCO}_{3}$ gradually stronger. By degrees it was brought up to 0.09 per cent. The urine now did not beeome red, but remained colourless; because the neutral red was beld back by the glomerular epithelium. Still it proved to be alkaline, for the addition of a little neutral red to the excreted urine brought about a faint orange colouring. Moreover, the retention of glucose was raised to more than 0.06 per cent., but for this it was necessary to increase the concentration of $\mathrm{CaCl}_{2}$ in the perfusion liquid from 0.0075 per cent. to almost double that percentage. This can be understood, because the $\mathrm{NaHCO}_{3}$ weakens the concentration of the $\mathrm{Ca}$ ions of the $\mathrm{CaCl}_{2}$, and it is on these that it greatly depends.

The question was now: Was the increase of the concentration of $\mathrm{NaHCO}_{3}$ to 0.09 per cent. sufficient?

To investigate this the alkalinity of the frog's serum was determined by the titration method of Snapper with neutral red paper as indicator. It appeared that this corresponded to a $\mathrm{NaHCO}_{8}$ solution of 0.285 per cent. Consequently, a Ringer's solution containing 0.285 per cent. instead of 0.09 per cent. $\mathrm{NaHCO}_{3}$ was prepared. Under these conditions it appeared that often more than 0.08 per cent. glucose, sometimes 0.12 per cent was retained. But then also the concentration of $\mathrm{Ca}$ had to be brought from 0.0075 per cent. to more than double that percentage.* The concentration of $\mathrm{NaCl}$ was lowered also because otherwise the $\mathrm{Na}$ concentration would have been too strong.

At this stage the question arose whether it would now be possible to obtain a sugar-free urine. According to Bang, the blood of the normal frog contains from 0.03 to 0.05 per cent. glucose. Would, therefore, the kidney be able to hold back all the glucose in a Ringer's solution which held 0.05 per cent. glucose and was rich in $\mathrm{NaHCO}_{3}$ ? The correspondence between the results of ten experiments showed that this was indeed the case; the urine was perfectly free from sugar. All sugar was held back, even when the Ringer's solution contained 0.08 per cent. glucose.

The glomerular epithelium is thus impermeable to free sugar. It is; therefore quite unnecessary to suppose the sugar to be present in the blood serum in the form of a colloidal compound in order to explain the fact that the urine of normal individuals is free from sugar (sucre virtuel of Lépine), a compound which as a matter of fact it has never yet been possible to isolate.

V. The Tolerance of the Kidneys to Glucose.

We come now to the second guestion which we put ourselves at the commencement of this article-namely, Why does sugar appear in the urine when the quantity of sugar in the blood exceeds a certain limit? or, to put it differently, What relation does there exist between hyperglycaemia and glycosuria? If we desire to make this out, we have to take account of the fact that glycosuria does not depend upon the quantity of glucose in the blood as a whole, but only on that fraction of it which occurs in the plasma. One is apt to lose sight of this, and take it for granted that these two quantities are one and the same. Without further thought it is assumed that if the blood contains $a$ per cent. glucose, the same is true for the plasma. This is true only when the sugar is distributed equally between plasma and blood corpuscles. As a general

* This concentration corresponds with the strength of that of the normal frog serum as found by Mr.de Waard by means of a micromethod worked out by himself: The description of this method will concentration varied with the seasons of the year. To this variation must be ascribed the fact that at the commencement of our investigations the results of our experiments on retention were so rule this is not the case, and certainly. not in man. + Should the blood corpuscles contain no sugar at all, and the sugar thus be present exclusively in the plasma then the plasma has to be considered as containing more than $a$ per cent glucose. The concentration of glucose in the plasma could then be determined from the relative volumes of blood corpuscles and blood plasma. Let us consider, for example, that 30 per cent. of the blood consists of blood corpuscles, the remaining 70 per cent. being plasma; then the plasma would contain $\left(\frac{1,0}{7} \times a\right)$ : per cent. glucose.

In consideration of these facts a large number of experi. ments have been conducted in connexion with the distribution of sugar in the blood of man, rabbit, and frog. We shall come back to this later. Suffice it to say here that the blood corpuscles in the circulating blood of the frog are quite free from sugar, and that the concentration of glucose in the plasma of the frog varies from 0.045 to 0.075 per cent., and that in the frog's blood as a whole from 0.03 to 0.05 per cent. These last figures correspond to those found by Bang.

In connexion with what has been discussed in the pre vious paragraph it may be expected that from a Ringer's solution containing 0.045 per cent. glucose a urine which is free from sugar will be obtained, and this proves to be.the case. Is it justifiable, then, to call a perfusion solution containing 0.06 per cent. glucose hyperglycaemic? No; because, as has been said already, there are frogs whoso plasma contains 0.075 per cent. glucose. With regard to this there are considerable individual differences, and we have found that the season of the year also has a great influence on the concentration of the sugar in the frog's plasma. What can be said is that a Ringer's solution containing 0.1 per cent. glucose may be considered hyper. glycaemic (better, hyperglucoplasmic). It appeared, in fact, that when that concentration of sugar was passed through the kidney a little of it was allowed to pass through with the urine.

The question now arose, How great would the retentive powers of the kidney become if the concentration of the glucose was raised above 0.1 per cent.? Experiments were conducted with solutions containing glucose concentrations of $0.11,0.12,0.15,0.2,0.25$, and 0.3 per cent. respectively. From the results of these experiments it appeared that the stronger the concentration of sugar in the solution the less glucose could be retained. Wlien the perfusion liquid contained 0.3 per cent. glucose, 0.3 per cent. was present in the urine as well; there was no retention of sugar in the least-a perfect glyeosuria therefore. A similar result was obtained when the concentration of glucose was 0.25 per cent. With a concentration of 0.2 per cent. a very small quantity of glucose was retained-namely, about 0.02 per cent.

In general it appeared that the more byperglyoaemic the perfusion solution was, the less sugar was retained. If a perfusion solution containing 0.07 per cent. glucose was used, then in the majority of cases all the sugar was retained. I say in the majority of cases, not always, and that can be understood-first, because for some frogs a solution containing 0.07 glucose means a fairly strong hyperglycaemia:; secondly, because the toleration of the kidneys of different frogs for glycosuria is not the same. For example, a frog whose blood contains 0.06 per cent. glucose will form urine free from sugar when a solution containing 0.07 per cent. glucose is passed through it. In the case of another frog under the same conditions sugar will pass into the urine. 'The toleration for hyperglycaemia is greater in the case of the first frog than in that of the latter.

As was said above, a Ringer's solution containing 0.3 per cent. glucose makes the glomerular epithelium perfectly permeable to sugar. One might say that the epithelium is sickened by it. The fact that a concentration of 0.3 per cent. glucose brings about a very slow formation of urine pleads for this view. We can put to ourselves the question, Is this change which the glomerular epithelium

+ In speaking of the concentration of sugar in the human blood this has therefore to be considered. It is customary, as has been remarked to ake for granted of glucose in the plasme whole. The fact is that neither in the case of man nor rabbit is a sugar equally distributed between blood corpusles and blood serum. This has been proved in our laboratory by numerous experiment made by different methods, and also from calculations and experiments by others. I On defibrination sugar passes from the blood serum to the blood
corpuscles (Brinkman). 
undergoes of a lasting nature? It appears that when afterwards a Ringer's solution containing more or less the physiological quantity - that is, 0.06 per cent. of glucoseis passed through the kidney, the urine contains sugar for several houns after, and that to the extent of 0.06 per cent. Whether the glomerular epithelium recovers again later we could not make out by our experiments.

We must admit that before these experiments we had a different conception of the origin of glycosuria from hyper. glycaemia. We had thought that when the perfusion liquid contained too much glucose the glomerular epithelium would remain impermeable to the sugar, but that the surplus would be excreted vicariously by the tubes. In this case the product from the glomerulus would be quite or nearly free from sugar. From the experiments, however, it appeared that this is not the case, and that, as has been said, in the case of strong hyperglycaemia, the glomeralar epithelinm allows even all the sugar of the perfasion liquid to pass through.

\section{The Behaviour of the lídneys towards} SOME IsOMERIC Sugaris.

As was explained in part IV, under normal conditions glucose as such is retained by the glomeralar membrane. If now we consider the fact that salts such as $\mathrm{NaCl}$ which, like glacose, are also crystalline, pass through it then arises the question, To what must this peculiar belsaviour of glucose be ascribed?

In the first place we might imagine that the molecule of the monosaccharide glucose $\left(\mathrm{C}_{6} \mathrm{H}_{12} \mathrm{O}_{6}\right)$ is so large that that would hinder its passage. We thonght that if this noticen was correct, then disaccharides, like sucrose, maltose, and lactose, which have still laxger molecule $\left(\mathrm{C}_{12} \mathbf{H}_{22} \mathbf{O}_{11}\right)$, would certainly be retained as well. The experiments proved, however, that the glomeralur epithedium is permeable to the three above-mentioned diseccharides to great degree. It is even perfectis permeablo to lactose; in fact, even ruffinose $\left(\mathrm{C}_{18} \mathrm{H}_{36} \mathrm{O}_{18}\right)$ is allowed to pass through it completely.

If, then, the retention of glucose could not be ascribed to the size of its molecule, there was the probability that a characteristic structare or configuration of the glucose molecule had something to do with it. For this reason some stgars which were either iscmeric or stereo-iscmeric with glucose were experimented with.

For convenience I give the formulae of a few of these sugars:

$$
\begin{gathered}
\text { Gaeose } \\
\text { (dextrose). }
\end{gathered}
$$

And what proved to be the case? That the fructose was allowed to pass through completely, likewise the mannose, while a small quantity of the galactose was retuined. 'The reader will not fail to notice how slight is the difference in the configurations of these four sugars, especially between the glucose and its stereo-isomeres salactose and mannose.

Glucose therefore occupies a very peculiar place amongst the isomeric monosaccharides with regard to the glomerular inembrane; or, to express it differently, the glomerular epithelinm has a power of separating glucose from the inonosaccharides in a way which suggests the relation of sugars to ferments. It is an established fact that a particular ferment can break up a particular sugar and others not. Sugar and ferment fit each other, as Emil Fischer expressed it, like a lock and key. If we apply this representation to our case, we would say that the lrey (glucose) does net fit the lock (glomerular membrane) and that the other sugars which have so far been experimented with do it.

It is deserving of attention that these investigations form a new illustration for the law of stereo-isomerism, but here it is not of a elemical, but of a physialogical naturelying, namely, in the domain of permeability.
Recently we have endeavoured to discover which group of the gineose molecule it is that imparts to this substance the peculiarity that causes it to be retained by the glomerular opithelium. With this end in view we have examined several other stereo-isomeric sugars, amongst others several pentoses.

At present we have a number of facts at our disposal, but we have not yet been able to make out to what glncose owes its "efficiency" of being retained by the glomerular epithelium. This property may well be called efficiency, for is it not an established fact that glucose is the most immediate source of muscular energy? It wonld be exceedingly inefficient if under normal conditions the sugat passed from the blood into the urine.

Be this as it may, we are certainly confronted here by a remarkable phenomenon when we consider that the laevo-rotatory glucose of the formula:

$$
\text { (-) }
$$

passes completely thirough the glomerular membrane. I will not dwell further upon these investigations, but make mention of only one fact, which is not without importance from a elinical point of view-namely, that when dextrose and laevulose are dissolved in the perfusion liquid, then the dextrose is again retained by the glomerular membrane, but the laevulose passes through. From this it is evident that the power of retention for dextrose is quantitatively not altered. The two sugars are simply separated from each other as through a filter; what is true for a mixture of dextrose and laevulose also applies to a mixture of glucose and lactose. The lactose passes completely into the urine and the glucose is retained by the glomerular epithelium to the same extent as when there is no lactose piesent.

\section{Some Further Remarks of a Theoretical} Practical Nature.

In the first place these are concerned with potassium. From the experiments made with weak concentrations of $\mathrm{NaHCO}_{3}$ - that is, with 0.02 per cent. ( $c f$. parts II and III) - it appeared (I have not mentioned this yet) that the $K$ could be omitted without the solution being affected for the worse. Both in the presence and absence of $\mathbf{K}$, 0.03 per cent. glucose was retained. If, however, $K$ was added, the quantity used had to lie within fixed limits. There had to be a definite relation between $\mathrm{Ca}$ and $K$. The question now was: Could the potassium also be left out of this new physiological perfusion liquid, in which the concentration of $\mathrm{NaHCO}_{3}$ was 0.285 per cent. (part IV), and if so, would it then be necessary, if $K$ was added to this solution, to balance it with $\mathrm{Ca}$ ? It appeared that in this case $K$ can be omitted, but that when it is added, the quantity is not of great importance to the retentive power. The accurate balancing between $\mathrm{Ca}$ and $\mathrm{K}$ is no onger necessary.

Several thoughts, not without impartance from a clinieg point of view, now urge themselves forward. In the first place one is disposed to think about the advanced stage of diabetes-the coma diabeticum. The patient suffers from acidosis. It is known that chiefly k-oxybutyric avid and areeto-acetic acid are formed, and these pass into the urine in the form of alts formed with the alkalis which they extract from the blood. It appears consequently that the alkalinity and also the concentration of $\mathrm{HCO}_{n}$ ions in the blood is considerably diminished; or, to express it in a simple way, the coneentration of $\mathrm{NaHCO}_{3}$ in the bloor plasma has beeome smaller, and consequently the humats kidney is in the same eondition as the frog's lzidney through which a liquid that contaims too little $\mathrm{NaHCC}_{3}$ streams.

It will be remembered that the concentration of $\mathrm{K}$ docs nat oscillate between wide margins, as was the case where the concentration of $\mathrm{NaHCO}_{3}$ in the perfugion liquid ws. normal ( 0.285 per cent.). It is known that in cases of diabetes the quantity of $\mathrm{K}$ in the urime is greater than with normal persons. This loss of $\mathrm{K}$ experienced by the 
blood plasma must be restored. We now ask ourselves the question whether it would not be efficient to give sucl patients besides the customary $\mathrm{NaH}^{-\mathrm{CO}_{3}}$ some $\mathrm{KHCO}$ also.

That the administering of $\mathrm{K}$ serves a good purpose is supported by the experience in connexion with the well known oatmeal cure. According to the analysis of Bunge $1 \mathrm{~kg}$. dried oatmeal contains 5 to 6 grams $\mathrm{K}_{2} \mathrm{O}$ against 0.1 to 0.4 per cent. $\mathrm{Na}_{2} \mathrm{O}$. One thus succeeds in bringins large quantities of $\mathrm{K}$ into the body. This is also effected with the potato cure of Mossé. Dried potatoes contain per kg. no less than 20 to 28 grams $\mathrm{K}_{2} \mathrm{O}$ against 0.3 to 0.6 gram $\mathrm{Na}_{2} \mathrm{O}$. Finally the following fact claims our attention : The ash of the normal pancreatic gland consists to a large extent of potassium phosphate; 100 grams dry ash contain 2.8 grams $\mathrm{K}_{2} \mathrm{O}$ and 0.04 gram $\mathrm{CaO}$. In the pancreas of a diabetic person, however, there is found to be present in 100 grams dry ash only 1.9 grams $\mathbf{K}_{2} \mathrm{O}$ and 0.17 gram $\mathrm{CaO}$. Here again $\mathrm{K}$ and $\mathrm{Ca}$ vary with respect to each other (Stoklasa).

From all this it may be gathered that the relation betwsen $K$ and Ca plays a part in glycosuria.

I could venture the following lypothesis, which, how ever, still requires extensive experimental control : As long as the concentration of $\mathrm{NaHCO}_{3}$ in the blood plasma is normal, even a moderate hyperglycaemia will cause no glycosuria. If, however, the $\mathrm{NaHCO}_{3}$ concentration is diminished, the glomerular epithelium has become sensitive to the propertions of $\mathrm{Ca}$ and $\mathrm{K}$ in the blood plasma A deficiency in the $K$ mast be met artificially, but the excretion of sugar can be prevented also to a large extent by increasing the conoentration of $\mathrm{NaHCO}_{3}$.

Be it finally said that Dr. Brinkman has made another investigation by the method described in connexion with the excretion of sugar in phloridzin diabetes. There is an extensive amount of literature on this form, and it is certain that phloridzin sets the normal kidney to excrete sugar even when the quantity of sugar in the blood is quite normal, and there is thus no question of hyperglycaemia. It is therefore renal diabetes. If this does not come about in patients after injection with phloridzin, then the tubular epithelium is looked upon as subnormal, for the normal tubular epithelium is regarded as possessing the power of absorbing the phloridzin and analysing it into glucose, which is excreted with the urine, and phloretin, which returns into the circulation, there to combine with more glucose forming new phloridzin. If the tubular epithelium is unable to analyse the phloridzin, the validity of the kidney leaves much to be desired.

Brinkman found that after the injection with phloridzin also the glomerular epithelium, in the case of the frog at least, takes an important part in the excretion of sugar.

If to the sugar-containing optimal perfusion liquid only 0.0004 per cent. phloridzin is added, then no trace of sugar is retained by the glomerular membrane. It is made perfectly permeable by it (the vena porta renalis was tied). In making out how much store can be set by the phloridzin experiment for determining the state of validity of the tubular epithelium one has thus henceforth to remember that phloridzin malkes the glomerular epithelium (at least that of the frog) to a great degree permeable to sugar.

\section{Summary and Conclusion.}

I. The glomerular membrane has the power of retaining fres ghucose.

II. This power is governed by the influence of the chemical composition of the perfusion liquid upon the glomerular epithelium. If this be the usnal Ringer's solution composed of $\mathrm{NaCl} 0.6$ per cent., $\mathrm{CaCl}_{2} 0: 0075$ per cent., $\mathrm{KCl} 0.01$ per cont., and $\mathrm{NaHCO}_{3} 0.02$ per cent., and to it has been added 0.1 per cent. glucose, then a urine contain. ing 0.07 per cent. glucose is excreted, 0.03 per cent. thus being retained. In the perfusion liquid the quantities of $\mathrm{K}$ and Ca with respect to each other can be altered in such a way that the retentive power noed not be influenced by it. In such a case they balance each other. Instead of using $k$ this balancing can also be effected by means of radinm and manium, that with doses which are determined not by equivalence in a chenrical sense, but by the degree of radio-activity. The subjection of the kidney to mesothorium rays can be substituted for $K$.

III. If the concentration of $\mathrm{NaHCO}_{3}$ in the Ringer's solution is raised from 0.02 per cent. to 0.285 per cent., the quantity which is present in the frog's serum, then the kidney can retain from the sugar.holding perfusion liquid more than 0.03 per cent. The artificial "urine" becomes totally free from sugar.

IV. These results deserve attention both from a theoretical-clinical and from a general biological point of view. From a theoretical-clinical, because the fact that the urine of normal individuals is free from sugar is at present brought down to a phenomenon of very nicely regulated permeability, and the conception of the colloidal sugar compound (sucre virtuel of Lépine), which, as a matter of fact, has never yet been isolated, is needless. The results are not without importance from a general point of view, because one is here confronted by a new form of permea. bility-one, namely, where cells under pliysiological conditions, although quite permeable to salts, are yet im. permeable to glucose, which like these is also a crystal. line-a species of permeability not hitherto observer and in casu very efficient.

V. The question arises to what the crystalline glucose is indebted for this quality, which is so efficient for the budy. 'There would be an inclination to seek it in the size of the molecule $\left(\mathrm{C}_{6} \mathrm{H}_{12} \mathrm{O}_{6}\right)$, but that lactose which posserses a still larger molecule $\left(\mathrm{C}_{12} \mathrm{H}_{22} \mathrm{O}_{11}\right)$, and even raffinose $\left(\mathrm{C}_{18} \mathrm{H}_{38} \mathrm{O}_{18}\right)$, pass through the glomerular menbrane. Nothing, then, remains but to consider the structure or configuration of the glncose molecule as being responsible for it. It has, indeed, appeared that the isoneric fructose and the stereo-isomeric mannose and galactose, and even the laevo-rotatory glucose (1-glucose) prss through the glomerular membrane. Thus the living glomerular membrane is able to distinguieh normal glacose from other sugars. From a theorotical point of view these results are also interesting, because in them may be seen a physiological illustration of the doctrine of stereo-isomerism.

VI. From the point of view of diagnosis especially it must be remarked that when, besides glucose (dextrose) fructose (laevulose) occurs in the perfusion liquid, only the laevulose is let through. The two sugars are separated as by a filter. What is true for a mixture of laevulose and dextrose applies also to a mixture of dextrose and lactose. The lactose passes completely into the urine, the glucose is retained by the glomerular epithelium as though there was no lactose present.

VII. Regarding the relation between glycosuria and liyperglycaemia the experiments have wade clear the following: If there is a hyperglycaemia of a certain degree then the glomerular epithelium sickens and allow: glucose to pass through. 'The higher the degree of hyper' glycaemia the stronger the permeability becomes. The toleration of the glomerular membrane for the sugar con centrations lying above the normal appears to be different for different individuals.

VIII. The investigations throw light on the customary therapentic measures taken in cases of advanced diabetes and the mechanism of phloridzin diabetes (part VII).

To forestall ąny misunderstanding let attention be called to the fact that it is by no means my purpose to do away with the significance of the tubular epitheliun. Thanks to the peculiar arrangement of blood vesseis in the kidney of the frog, the investigations in question coulc only bear exclusively upon the behaviour of the glomerular epithelium.

BIBLIOGRAPHY

Cammidge, Glycnsuria and Allied Conditions.

H. J. Hamburger and R. Brinkman: Prreeedings Koninklyli, Akademie van Wetenschappen, A misterdan. Neeting of Jannary

(biochem. Zeitschr. 88, 97, $1918: 93,1919$ (still to appear)

R. Brinkman: Quart. Journ. of Exper. Physiology, 1918.

H. J. Hamburger and D. J. de Waard: Compt. rend., 165, 372 (1917 D. J. de Waard: Biochem. Zeitschr., 1919 (still to appear).

THE Spanish Government has under consideration a bil presented in the Senate providing that disability contracted in the exercise of professional work shall be regarded as an occupational accident and for the grantin. of pensions to widows and orphans of men who have died in consequence of inoculations and contagious diseases. The amount specifled is 2,000 pesetas ( 280 ) in towns of 200,000 or more inhabitants and 1,000 pesetas $(£ 40)$ in towns of less than 10,000 inhabitants, with intermediate amounts. 